ORIGINAL ARTICLE

\title{
Buying a handgun for someone else: firearm dealer willingness to sell
}

\section{S B Sorenson, K A Vittes}

\begin{abstract}
Objective: To examine firearm dealer willingness to sell when a handgun is being purchased for another person. US law requires a background check of the purchaser but not the end user of a firearm.

Subjects and methods: A total of 120 handgun dealers (six from each of the 20 largest US cities with 10 or more dealers) participated in telephone interviews. Dealers within each city were randomly assigned to a male or female interviewer and then randomly assigned to one of three purchase conditions - when the consumer said that the handgun was for him/herself, a gift for a girl/boyfriend, or for a girl/boyfriend "because s/he needs it".

Results: Most dealers were willing to sell a handgun regardless of the end user (self: $87.5 \%$; gift: 70.8\%; "need": $52.5 \%$ ). Multivariate analyses indicate that dealers in the Midwest, South, and West were more willing to sell than those in the Northeast (adjusted odds ratio $(A O R)=21.30,18.74$, and 8.93 , respectively) and that willingness to sell is lower when the sale would be illegal, that is, under the "need" condition (AOR = 0.20).

Conclusions and implications: Dealers are in a position to exercise judgment when a customer is explicit about buying a firearm for someone else. Some appeared willing to ignore or sidestep relevant information even when told that the end user was prohibited from purchasing a firearm him/herself. In the absence of federal handgun registration, which would track ownership changes, resources with which to conduct compliance checks (for example, as are conducted to identify retailers who sell tobacco or alcohol to under-age persons) seem warranted.
\end{abstract}

See end of article for authors' affiliations

Correspondence to: Professor Susan B Sorenson, UCLA School of Public Health, 650 C E Young Drive South, Los Angeles, CA
90095-1772, USA sorenson@ucla.edu r n the US, efforts to reduce firearm related morbidity and mortality include keeping guns out of the hands of certain people (for example, felons, those adjudicated mentally ill). Regulating the actions of all people who purchase guns in the US (over four million domestically produced guns were sold in the US in 1999') is extremely difficult. Regulating firearm dealers is one such effort to assert control over who is able to obtain a firearm. A federal firearms license (FFL) is required of anyone who is "regularly involved in the business of selling firearms at wholesale or retail" the US in 2001. ${ }^{1}$ FFLs, which are subject to federal oversight, are the point of purchase of most $(60 \%-70 \%)$ guns each year.

One focus of recent firearm policy debate is whether and how to require firearm manufacturers to take responsibility for the distribution of their products. More than 30 US cities and counties have filed lawsuits, many on this basis, against firearm manufacturers trying to hold them accountable for firearm violence. As noted in some of the legal cases, it is believed that many gun dealers facilitate-sometimes willingly and sometimes passively - the movement of guns from the legal to the illegal market. ${ }^{4}$ The primary observation is that, despite laws and regulations, individual dealers are able to exercise a fair amount of judgment in their sales of firearms. To our knowledge, published peer reviewed literature on firearm dealer sales behavior is virtually non-existent.

In the present study, we focus on firearm dealers and their willingness to sell a handgun in a situation like a "straw purchase". A straw purchase is defined as when a person who is authorized to purchase a firearm buys one for someone who is not so authorized (for example, a felon ${ }^{6}$ ) or when the purchaser conceals "the identity of the true intended receiver of the firearm(s)" (Department of the Treasury, Bureau of Alcohol, Tobacco, and Firearms; glossary $\left.{ }^{7}\right)$. Under federal law, a person may not knowingly purchase a firearm for a person who is prohibited from doing so him/herself, and dealers are prohibited from selling or delivering "any firearm to any person in any state where the purchase or possession by such person of such firearm would be in violation of any state law or any published ordinance ...". ${ }^{8}$

We focus on handguns rather than shotguns or rifles because handguns are used disproportionately in crime and suicide. $^{79^{10}}$ We also examine the role of purchaser gender. Women are not common purchasers of firearms; only $8 \%$ of women (compared with 35\% of men) have ever purchased a handgun. ${ }^{11}$ A widely held belief among law enforcement is that when a woman buys a handgun, she is buying it on behalf of her boyfriend or husband; available data support this assumption. ${ }^{12}$ And, friends and family are the primary persons who are asked to and who do purchase guns for firearm traffickers, incarcerated offenders, and high school students. ${ }^{13-15}$ In addition, recent research suggests that female gender is the single largest correlate of multiple purchase handguns, guns that may be more likely than others to be used in crime ${ }^{16} \mathrm{We}$, therefore, examine whether the intended user affects firearm dealer willingness to sell.

\section{METHODS}

Six handgun dealers from each of the 20 largest cities in the US that had 10 or more dealers participated in the research. (A power analysis was conducted before data collection to determine the number needed to detect meaningful differences.) A list of US cities, ranked by size, was used to identify potential cities. ${ }^{17}$ We identified dealers listed in an internet business directory under the keywords of "guns", "gun dealers", and "firearms".

Cities with fewer than 10 dealers listed were eliminated and replaced with the next largest city. Six firearm dealers were randomly selected from the listings for each city. Additional dealers were randomly selected when necessary (for example, 
when a dealer did not sell handguns). Dealers were grouped by region of the country into Northeast (Baltimore, New York City, Philadelphia), South (Memphis, Nashville, Jacksonville, Oklahoma City, Houston, Dallas, San Antonio, El Paso, Austin, Fort Worth), Midwest (Cleveland, Indianapolis), and West (Denver, Seattle, Phoenix, Los Angeles, San Diego). Population sizes ranged from over eight million (New York City) to about one half million (Oklahoma City).

Dealers within each city were randomly assigned to one of two interviewers, one male and one female. Interviewers called the sampled firearm dealers posing as potential handgun purchasers. Interviewers followed a predetermined script that began with "Hi, do you sell handguns?" If not, the dealer was thanked and the call was terminated. If the dealer said yes, the interview continued with one of three a priori randomly assigned conditions, specifically: (1) "I'm looking to buy a handgun for myself," (2) "I'm looking to buy a handgun for my girl/boyfriend for her/his birthday," or (3) the intentionally ambiguous situation of "My girl/boyfriend needs me to buy her/ him a handgun". The interviewer continued with "I've never done this before. What do I need to know?" The script and answers to anticipated questions (for example, "How much do you want to spend?") were pilot tested with 10 gun dealers across the US who were not from the sampled cities. Each pilot call was observed by the other interviewer and an attempt was made to standardize tone, style, and other speech patterns.

The callers took notes during all interviews and completed a brief questionnaire immediately after each call. Participation rate was $100 \%$. Clerks who answered the phone were not made aware that they were participating in a study.

Attempts to persuade can reasonably be expected to be used by potential purchasers, therefore, when a clerk was unwilling to sell a handgun to the caller, the interviewers were instructed to gently attempt to persuade him or her (for example, "Is there any way I can do this-is there any way we can work it out?"). Five of the 28 conversion attempts were successful; we classified the converted cases $(n=5)$ as willing to sell. Ten clerks gave a response that could not be classified as a clear yes or no which was recorded as a "might" or "maybe". Given that an equivocal response is not a likely outcome in an in-person transaction, we adopted a conservative approach and required an affirmative response for inclusion in the "willing to sell" category; when a dealer indicated that s/he "might" sell, it was coded as a "no".

Frequencies and Fisher's exact tests were calculated to examine differences related to the manipulated variables, that is, interviewer gender and sales condition. Multivariate logistic regressions that took into consideration study variables (that is, interviewer gender and sales condition) and geographic region were used to predict dealer willingness to sell. Likelihood ratio tests were used to determine whether adding geographic region to the regression significantly improved the fit of the model. We also conducted descriptive and multivariate logistic regression analyses examining the role of the legality of the sale.

Under federal law, licensed firearm dealers may legally sell a firearm to any person who is not a prohibited purchaser (for example, a convicted felon) including guns that will be given as a gift. ${ }^{78}$ In most cases, however, a licensed dealer may not knowingly sell a firearm to someone who the dealer knows is not the intended possessor, independent of the intended possessor's eligibility. ${ }^{19}$ To determine whether it is legal under state laws for a dealer to sell a handgun when purchased as a gift, we contacted nine law enforcement agencies in seven different states. Responses ranged from the openly unsure (for example, "That's a tricky question right there") to the tentative (for example, "I'm pretty sure it's legal") to the accusatory ("I've been on the job 12 years and never had a person ask the law if they weren't going to do something illegal"), to the incorrect (for example, "Federal law says no for handguns"). Given this inconsistent information, we sought the assistance of two attorneys, a former Assistant United States Attorney and an attorney specializing in firearm policy. They reviewed relevant federal and state statutes ${ }^{18} 20$ and judged whether it was legal for the dealer to sell a handgun under each condition in the specific state. The independent evaluators differed only on whether the gift condition was illegal in Indiana. Data were analyzed with Indiana classified each way; substantive findings were the same. To facilitate presentation of the findings, results are presented with Indiana classified as allowing gift sales.

The research was reviewed and approved by UCLA's Internal Review Board.

\section{RESULTS}

\section{Willingness to sell}

Most $(70.8 \%)$ dealers indicated that they were willing to sell a handgun to the caller regardless of the stated end user of the gun. Willingness to sell differed by sales condition $(p=0.003)$. As shown in table 1, dealers were willing to sell a handgun $87.5 \%$ of the time when the caller stated that the handgun was for him/herself. (Dealer refusal to sell under this condition occurred when the interviewers, when asked, revealed that they did not meet residency or license requirements for the purchase.) When the caller stated that the handgun would be a gift, $72.5 \%$ of the dealers indicated they would sell the gun. One half $(52.5 \%)$ indicated they would sell a handgun to the caller when told it was for a girl/boyfriend "who needs it".

Dealers were equally willing to sell a handgun to male and female callers $(70.0 \%$ v $71.7 \%)$. (When "maybe" was included as a category, male callers were more likely to be given an outright "no" (28.3\% v 13.3\%), whereas females were more likely to be told that she "might" be able to get the gun $(15.0 \% \mathrm{v}$ 1.7\%).) Although the proportion of dealers who were willing to sell a handgun when it was for the girl/boyfriend was identical $(62.5 \%)$ for the interviewers, the proportion differed according to the rationale provided: a higher proportion were willing to sell to the male than the female interviewer when the gun would be a gift $(80.0 \% v 65.0 \%)$ but a lower proportion were willing to sell to him than her when it was for a girl/boyfriend who needs it $(45.0 \% \vee 60.0 \%)$.

A finding that emerged from the data, not postulated a priori, is that of geographic region. Dealers in the Northeast were

\begin{tabular}{|c|c|c|c|c|}
\hline & \multicolumn{4}{|c|}{ Randomly assigned handgun purchase condition } \\
\hline & \multirow[b]{2}{*}{ For self $(n=40)$} & \multicolumn{2}{|c|}{ For girl/boyfriend } & \multirow[b]{2}{*}{$\begin{array}{l}\text { Total } \\
(n=120\end{array}$} \\
\hline & & As gift $(n=40)$ & $\begin{array}{l}\text { Because } s / \text { he needs it } \\
(n=40)\end{array}$ & \\
\hline \multicolumn{5}{|l|}{ Interviewer gender } \\
\hline Male $(n=60)$ & 85.0 & 80.0 & 45.0 & 70.0 \\
\hline Female $(n=60)$ & 90.0 & 65.0 & 60.0 & 71.7 \\
\hline Total $(n=120)$ & 87.5 & 72.5 & 52.5 & 70.8 \\
\hline
\end{tabular}


substantially less likely to agree to sell than dealers in other regions of the country $(27.8 \% \vee 78.4 \% ; \mathrm{p}=0.001)$, and those in the South were more likely than those elsewhere to agree to sell a handgun $(81.7 \%$ v $60.0 \% ; \mathrm{p}=0.015)$.

\section{Handgun dealers and the law}

Selling a handgun would be illegal under the "need" condition ( $\mathrm{n}=40$ ), yet one half $(52.5 \%)$ of the dealers were willing to do so. If the sale was legal, $80.0 \%$ were willing to do so. The legality of the sale was related to dealer willingness to sell ( $\mathrm{p}=$ 0.003 ). Some dealers appeared to be aware of, but willing to work around, limitations placed by the law, as evidenced by the following exchanges: Interviewer: "Is there a problem with me buying it for my girlfriend?" Dealer: "As long as we don't know about it. It's personal business". Or, "First thing, don't ever tell anyone you're buying a gun for someone else because it's against the law". In several cases, dealers suggested that the caller contact another specific dealer, indicating that they may be aware of someone who might be willing to sell under these circumstances.

\section{Multivariate analyses}

Multivariate logistic regressions were used to assess the independent effect of the type of sale, caller gender, and geographic region. The first regression tests the role of interviewer gender and type of sale (see table 2, model I). Dealers were less likely (adjusted odds ratio $(\mathrm{AOR})=0.38)$ to say that they would sell a handgun intended to be a gift than for personal use. Although this finding is substantively important, it is not of statistical significance $(p=0.11)$. Dealers were less willing $(\mathrm{AOR}=0.16 ; \mathrm{p}=0.001)$ to sell a handgun if the caller indicated it was a purchase intended for a girl/boyfriend because s/he "needs it".

Adding geographic region to the regression (see model II) improved the fit of the model substantially $(p=0.001)$ and the added variables were statistically significant. Dealers in the Midwest, South, and West were more willing than those in the Northeast to sell regardless of the recipient of the handgun or the gender of the caller $(\mathrm{AOR}=21.30, \mathrm{p}=0.003$; $\mathrm{AOR}=$ $18.74, \mathrm{p}=0.000 ; \mathrm{AOR}=8.93, \mathrm{p}=0.004$, respectively $)$. "Need" remained significant $(\mathrm{AOR}=0.09, \mathrm{p}=0.001)$.

All "need" sales were illegal; the others were legal. Replacing sale type with sale legality in models I and II resulted in an AOR of 0.28 (95\% confidence interval (CI) 0.12 to 0.63 ) for illegal sales; the AOR for interviewer gender remained the same. When region was added to the regression, the AOR for interviewer gender and each region did not change substantially. Illegal sales remained statistically significant $(\mathrm{AOR}=$ $0.20,95 \%$ CI 0.08 to 0.53 ).

\section{DISCUSSION}

Firearm dealers who sell handguns are generally willing to sell to a potential customer regardless of whether the gun is for his or her own use or for use by another person. Gender of the purchaser was generally not relevant. Dealers in the Midwest, South, and West were more likely than those in the Northeast to be willing to sell a handgun regardless of interviewer gender and sales condition. Although dealers were less willing to make a sale when it would be illegal, more than half were willing to sell a handgun even when it would be illegal to do so.

This is, to our knowledge, the first study in the peer reviewed literature on factors that might influence firearm dealers' willingness to sell a handgun. The strengths of the study include its design (for example, see Campbell and Stanley ${ }^{21}$ ). The population included all dealers listed in the yellow pages of an internet directory, an easily accessed source of information for many persons wishing to purchase a firearm. Participating dealers were selected from large US cities in states that contain over half $(53 \%)$ of the US population ${ }^{22}$ and $35.5 \%$ of the FFLs (federal firearm licensees) in the US. ${ }^{1}$

Several matters warrant comment when interpreting the findings. First, dealers' stated intent may not correspond to their actual behavior. Although not necessarily a usual business practice, some dealers may say that they would sell a handgun while on the telephone but not do so if the potential customer was on-site. Alternatively, some dealers might resist persuasion attempts on the telephone but might yield to in-person pressure. Second, employees likely vary in their knowledge of and compliance with firearms laws such that if an interviewer had spoken with a different clerk at the same retailer, s/he might have received a different answer. Although personnel training may vary across and within stores, one "bad" clerk can implicate the entire dealership. Third, the effect of price on willingness to sell is not clear. If asked how much they were willing to spend, interviewers stated "about $\$ 300 "$. Handguns are available for less and for substantially more. Perhaps dealer behavior would differ depending upon the amount of money a customer was willing to spend. Fourth, the effect of dealer location (that is, rural or urban) is unknown because the sample included only urban dealers. Fifth, the effect of state level regulation of firearm dealers is not examined in this study. Sixth, we did not attempt to ascertain whether the participating dealers held FFLs. One could assume that, if listed in a telephone directory, the dealer is "regularly involved in the business of selling firearms at wholesale or retail" and should have an FFL. ${ }^{2}$ It was not possible, however, to ascertain this information without arousing undue suspicion. And, finally, although only two or three dealers seemed to be suspicious of the interviewers, skeptics may wonder whether the dealers were simply "playing along" with the caller.

To address the latter concern, we made 20 additional calls after the study was complete. A dealer was randomly chosen from each city and randomly assigned to each interviewer. The interviewer opened with "My girl/boyfriend needs me to buy

\begin{tabular}{|c|c|c|c|c|}
\hline & \multicolumn{2}{|c|}{ Model I } & \multicolumn{2}{|c|}{ Model II } \\
\hline & AOR & $95 \% \mathrm{Cl}$ & AOR & $95 \% \mathrm{Cl}$ \\
\hline \multicolumn{5}{|l|}{ Study condition } \\
\hline Gift (v for self) & 0.38 & 0.12 to 1.21 & 0.28 & 0.07 to 1.09 \\
\hline Need & 0.16 & 0.05 to 0.49 & 0.09 & 0.02 to 0.36 \\
\hline \multicolumn{5}{|l|}{ Interviewer gender } \\
\hline Female ( $v$ male) & 1.09 & 0.48 to 2.51 & 1.12 & 0.44 to 2.82 \\
\hline \multicolumn{5}{|l|}{ Geographic region } \\
\hline Midwest (v Northeast) & & & 21.30 & 2.82 to 161.17 \\
\hline South & & & 18.74 & 2.05 to 38.9 \\
\hline West & & & 8.93 & 4.54 to 77.36 \\
\hline
\end{tabular}

$A O R$, adjusted odds ratio; $\mathrm{Cl}$, confidence interval.

Note: each regression took into account the variables that are listed. 


\section{Key points}

- A primary focus of both criminal justice and public health efforts has been keeping guns out of the hands of those who should not have them.

- The US government has allocated the primary responsibility to firearm dealers for monitoring that guns are not sold to persons who are prohibited by law from buying one.

- An experimental study of handgun dealers in the 20 largest cities in the US found that dealers generally are willing to sell to a potential customer regardless of whether the gun is for his or her own use or for use by another person.

- Although dealers were less willing to make a sale when the sale would be illegal, more than half were willing to sell a handgun even when it would be illegal to do so.

her/him a handgun because s/he isn't allowed to". That is, the caller was explicit about wanting to buy a gun for a prohibited purchaser. In 16 of the 20 calls, the dealer responded with an unequivocal "no" and commented about such a purchase being clearly illegal, a straw purchase, etc. Each of the four who agreed to sell a handgun appeared to recognize that the sale would be illegal. They said: (1) "As long as you have no record, you can come down here and pick one up and put it in your name"; (2) "You can do whatever you want after you walk out the door"; (3) "What you do with it is your business. Legally you'd be responsible for it, you're more than welcome to buy one. You can't transfer it to him-I assume he's been turned down"; and (4) "She can't come in, pick one out and you buy it. That's against the law". Interviewer: "I'd come, just me". Clerk: "I'd have no problem with that". These comments suggest that, even when expressly prohibited by law, dealer judgment enters into their sales.

\section{Implications for prevention}

Buying a handgun for another person may be a generous act intended to improve the recipient's ability to protect him/ herself. It also can provide legal cover for the recipient of the firearm because $\mathrm{s} / \mathrm{he}$ is not subject to a background check or other regulatory mechanisms. Background checks are far from perfect, ${ }^{23}$ but they are the primary means for screening those seeking to buy a firearm. It might be worth considering whether to prohibit purchasing or selling guns as gifts or, more generally, to prohibit purchasing or selling a firearm for someone else. Individuals are already prohibited from purchasing a firearm for a felon or other unauthorized purchaser; not allowing any firearm purchase on behalf of another would be useful when the purchaser or dealer is unaware of the recipient's relevant background. Alternatively, it might be worth considering changing the law to require a background check of the recipient of the firearm as well as the purchaser.

Regulating gun transfers (for example, requiring transfers between private parties to go through an FFL), as some states already do, is another potentially promising method to decrease gun injuries and fatalities. ${ }^{24}$ Such approaches necessitate consideration given that current law enables people to break, with relative ease, the link between a firearm and the individual who uses it. If firearms were registered, transfer of ownership could be tracked more easily, and options and considerations such as those listed in the previous paragraph would be less relevant.

Educating retailers and enforcing existing laws are two other ways to reduce illegal sales. Decoy operations in which law enforcement agents impersonate a customer could help identify errant dealers. Such approaches have been used in cigarette and alcohol sales to minors.

Recent data indicate that $57.4 \%$ of crime guns can be traced to $1.2 \%$ of FFLs, ${ }^{7}$ and sales volume, although an obvious cov- ariate, appears not to be a determining factor. ${ }^{25}$ Likewise, in the aforementioned General Accounting Office investigation, almost all FFLs adhered to federal and state firearm purchase laws. ${ }^{23}$ Our findings differ. About half of the dealers were willing to sell a handgun when such a sale would be illegal. In addition, a few dealers seemed to be aware that such action would be illegal in that they indicated that they would be willing to skirt, if not openly violate, the law or they referred a potential customer to another retailer who may be so inclined.

\section{Authors' affiliations}

S B Sorenson, K A Vittes, UCLA School of Public Health, Los Angeles, California

\section{REFERENCES}

1 Department of the Treasury, Bureau of Alcohol, Tobacco, and Firearms. Firearms commerce in the United States 2001/2002. Washington, DC: US Department of the Treasury, Bureau of Alcohol, Tobacco, and Firearms, 2002.

218 USC $\S 921$ (a)(11))

3 Cook PJ, Ludwig J. Guns in America: results of a comprehensive national survey on firearms ownership and use. Washington, DC: Police Foundation, 1997

4 Vernick JS, Teret SP. New courtroom strategies regarding firearms: tort litigation against firearm manufacturers and constitutional challenges to gun laws. Houston Law Review 1999;36:1713-54.

5 Gun Control Act of 1968. 18 USC $\$ 922$ (b)(2).

6 Veen J, Dunbar S, Reuland M, et al. The BJA firearms trafficking program: demonstrating effective strategies to control violent crime. Police Executive Research Forum. Series: BJA Bulletin, 1997.

7 Department of the Treasury, Bureau of Alcohol, Tobacco, and Firearms. Following the gun: enforcing federal laws against firearms traffickers. Washington, DC: Department of the Treasury, Bureau of Alcohol, Tobacco, and Firearms, 2000.

8 Gun Control Act of 1968, 18 USC § 922 (d) and (g).

9 Zawitz MW. Guns used in crime: firearms, crime and criminal justice: selected findings. Washington, DC: National Institute of Justice, 1995 (publication number NCJ-148201).

10 Wintemute GJ, Teret SP, Kraus JF, et al. The choice of weapons in firearm suicides. Am J Public Health 1988;78:824-6.

11 National Opinion Research Center. National gun policy survey 1998 Chicago: University of Chicago, 1999.

12 Wachtel J. Sources of crime guns in Los Angeles, California. Policing: An International Journal of Police Stategies and Management 1998;21:220-39

13 Wright JD, Rossi PH. Armed and considered dangerous: a survey of felons and their firearms. Expanded edition. New York: Aldine de Gruyter, 1994

14 Beck A, Gilliard D, Greenfeld L, et al. Survey of prison inmates, 1991. Washington, DC: National Institute of Justice, 1993 (publication number NCJ-136949).

15 Sheley JF, Wright JD. Gun acquisition and possession in selected juvenile samples: research in brief. Washington, DC: National Institute of Justice, 1993 (publication number NCJ-145326).

16 Wright MA, Wintemute GJ, Romero MP. A case-control study of multiple purchase handguns: characteristics that predict their use in crime. Presented at the APHA annual convention, November 10-13, 2002, Philadelphia, PA.

17 Bureau of the Census. 1990 Census of population: population of the 100 largest urban places. Washington, DC: Bureau of the Census: table 22.

18 Department of the Treasury, Bureau of Alcohol, Tobacco, and Firearms. Federal firearms regulations reference guide. Washington, DC: Department of the Treasury, Bureau of Alcohol, Tobacco, and Firearms, 2000.

19 Department of the Treasury, Bureau of Alcohol, Tobacco, and Firearms. General information. Available at: http://www.atf.treas.gov/ pub/fire-explo pub/geninfo.htm.

20 Department of the Treasury, Bureau of Alcohol, Tobacco, and Firearms. State laws and published ordinances-firearms. 22nd Ed. Washington, DC: Department of the Treasury, Department of the Treasury, Bureau of Alcohol, Tobacco, and Firearms, 2000.

21 Campbell DT, Stanley JC. Experimental and quasi-experimental designs for research. Boston: Houghton Mifflin, 1963.

22 US Census Bureau. Ranking tables for states: population in 2000 and population change from 1990 to 2000 . Available from URL: http://www.census.gov/population/cen2000/phc-t3/tab03.pdf

23 General Accounting Office. Firearms purchased from federal firearm licensees using bogus identification. Washington, DC: US General Accounting Office, 2001

24 Cook PJ, Molliconi S, Cole T. Regulating gun markets. J Crim Law Criminol 1995;86:59-92.

25 Wintemute GJ. Relationship between illegal use of handguns and handgun sales volume. JAMA 2000;284:566-7. 


\section{PostScript}

\section{RESEARCH LETTERS}

\section{Can martial arts falling techniques prevent injuries?}

Although falling techniques are taught to martial artists, athletes and paratroopers, $B M J$ search of Highwire listed journals has discovered no mention of "falling correctly" "safe falling", etc. "Reducing the force of impact of a fall on people's bones" is discussed. ${ }^{1}$ But the literature mentions no impact reduction techniques except for hip protectors. Exercise and muscle power in old age are recognized as helping regain balance after tripping, ${ }^{2}$ but not all falls are preventable. So perhaps safe falling should also be explored.

One finds discussion of types of fall, with no discussion of those who were trained in falling. ${ }^{3}$ Studies of reactions to slipping do not distinguish athletes and martial artists from other healthy subjects. ${ }^{4}$ Tai Chi is mentioned as appropriate exercise for the prevention of falls, ${ }^{5}$ but unlike the Japanese arts, Tai Chi does not teach falling.

Although correct falling is neglected in the medical literature, there is much semiscientific literature by martial arts masters An internet search for ukemi yields useful information.

The ease with which martial artists take even very hard falls suggests the hypothesis that falling practice while relatively young can prevent injury from falls incurred later in life.

A Japanese study of 11 deaths and serious injuries in aikido from 1972-75, listed eigh due to falling. ${ }^{6}$ Most of the victims were relative beginners, suggesting that those who practice over long periods are more protected.

However, the study population is too small to permit definitive conclusions, nor is it known how many such injuries may have gone unreported. The author admits that: "some universities were not particularly cooperative" in supplying data. New students who had suffered injury or death had been submitted to excruciating training with many repetitive falls, suggesting that the injury protection benefits of martial arts skills must be balanced against risks accompanying the process of acquiring the skills. And literature searches reveal no biomechanical evidence that martial arts falls result in fewer peak forces on the body than do everyday falls.

Martial arts tend to have rather specialized falling techniques. Aikido falls may not protect you in cases where judo falls will be effective. There seem to be no studies of the angles of falls most likely encountered in daily life, and what techniques would be generally most preventative. Martial arts practice is so strenuous that it is unlikely that large numbers will take it up. There may be an upper limit to the age at which one can start practice, although anecdotally it is not unknown to begin in one's late 50s, and at least one Japanese businessman started aikido at 70 and reached the black belt.

It is not known whether the teachers involved in the tragedies cited above had training in health sciences or injury prevention. Many martial arts teachers take extreme care for the safety of trainees, and some are health professionals.

There is plenty of anecdotal evidence of martial artists coming out safely from quite dangerous falls. So although martial arts falling techniques may not be a solution for the general population, they may be so for a minority. It remains to be seen whether safe and enjoyable methods might be developed to teach selected falling techniques to the general population.

\section{Acknowledgement}

I thank L Katz of Budo Ninjutsu for much helpfu advice.

\section{F J Leavitt}

Centre for Asian and International Bioethics, Faculty of Health Sciences, Ben Gurion University of the Negev, Beer Sheva 84105, Israel yeruham@bgumail.bgu.ac.il

\section{References}

Chakravarty M, Sorman A. Guidelines for prevention of falls in people aged over 65 . BM 2001;322:554 [letter].

2 Skelton DA, Beyer N. Exercise and injury prevention in older people. Scand J Med Sci Sports 2003:13:77.

3 Ellis AA, Trent RB. Do the risks and consequences of hospitalized fall injuries among older adults in California vary by type of fall? J Gerontol A Biol Sci Med Sci 2001;56:M686-92.

4 Marigold DS, Bethune AJ, Patla AE. Role of the unperturbed limb and arms in the reactive recovery response to an unexpected slip during locomotion. J Neurophysiol 2003;89:1727-37.

5 Feder G, Cryer C, Donovan S, et al. Guidelines for the prevention of falls in people over 65. BM 2000;321:1007-11.

6 Shishida F. Aikido and injuries: special report. Aiki News 1989;80 (April); partial English translation of article in Nihon Budo Gakkai Gakujutsushi (Scientific Journal of Japanese Martial Arts Studies) 1988;21(1) Available at: http://www.aikidojournal.com/ articles/_article.asp?ArticleID=497 (accessed 24June 2003).

\section{New trends in suicide in Japan}

Suicide is the 10th leading cause of mortality in the world. It is just as common as road traffic deaths ${ }^{1}$ and a leading cause of death among the young. 2002 was the fifth consecutive year where there were more than 30000 suicide deaths. The rate in Japan, 25 per 100000 , greatly exceeds that of the UK (7.4 per 100000 ) and that of the US or Germany, 12 and 15.8, respectively. ${ }^{2}$ In 2002, 32143 suicides were reported; this is an increase of 3.5\% from 2001

In Japan suicide victims are mostly young adults. Among those $15-24$ and $40-54$ it is the second leading cause of death and in 25-39 year age group it is the leading cause of death. ${ }^{2}$ The rate in middle aged men (40-54 years) was five times higher than in women, perhaps because of the association between suicide, unemployment, and economic recession. ${ }^{3}$

The suicide rate per 100000 population in Japan increased from 1995 to 2000 : 17.2 in 1995, 25.4 in 1998, 25.0 in 1999, and 24.1 in 2000 (source: Vital Statistics $2000^{2}$ ).

Suicide is a public health problem that requires an evidence based approach to prevention. ${ }^{4}$ The stigma associated with suicide and mental illness prompts the view that these are shameful or sinful conditions. This is also a barrier to treatment for persons with suicidal desires or who have attempted suicide in the past. ${ }^{5}$ Many suicides are preventable but as with other injuries, effective suicide prevention programs require commitment and resources. ${ }^{6}$

\section{Acknowledgement}

This brief review is supported by the Japan Society for promotion of Sciences (JSPS).

E B R Desapriya*†, N Iwase* Institute of Social Sciences, University of Tsukuba Ibaraki, Japan* and BC Injury Research and Prevention Unit, Centre for Community Health Research, Vancouver, Canadat; edesap@cw.bc.ca

\section{References}

1 Murray CJL, Lopez AD. Global health statistics: a compendium of incidence, prevalence, and mortality estimates for over 200 conditions. Cambridge, MA: Harvard University Press, 1996.

2 Ministry of Health and Welfare. Vital statistics 2000. Tokyo, Japan: Ministry of Health and Welfare.

3 Takei N, Kawai M, Mori N. Sluggish economic affects health of Japanese business warriors. Br J Psychiatry 2000; 176:494-5.

4 De Leo $D$. Struggling against suicide: the need for an integrative approach. Crisis 2002:23;23-31

5 Desapriya EBR, Iwase N. Stigma of mental illness in Japan. Lancet 2002:359:1866.

6 Maris RW, Berman AL, Silverman MM. Treatment and prevention of suicide. Comprehensive text book of suicidology. New York: Guilford, 2000: 509-35.

\section{LETTERS}

\section{Further reflections on the seatbelt use and effectiveness issue}

In a recent letter, Cummings and Rivara ${ }^{1}$ mis state my point regarding changes in estimated belt effectiveness in the mid-1980s using the comparison of front seat occupant pairs. They cite my statement, "What is not explained by the theory [about misclassification of seatbelt use by police] is the sudden gap in police reported use by the dead and survivors that appeared in the mid-1980s" $\mathrm{s}^{2}$ as faulting them for not explaining why prevalence of seatbelt use changed from 1975 to 1998. How could anyone who uses the English language with a modicum of proficiency interpret "sudden" as 23 years and "gap in police reported use by the dead and survivors" as general prevalence of belt use?

Actually, a cursory look at the graph in Cummings paper that I critiqued indicates that the major reduction in risk ratios indicative of seatbelt effectiveness occurred during a short period in the mid-1980s when belt use laws were being debated and initially enacted in a few states. I noted that this debate could have changed police behavior in belt use classification in crashes, a point they ignored. I also pointed out that reductions in deaths related to on-road observations of belt use 
prevalence controlling for other factors do not support their claim of $65 \%-70 \%$ belt effectiveness when used, a point they ignored.

I understand the distinction between what they call differential and non-differential misclassification. In a 1976 paper, I indicated how a small systematic error by police in assessing belt use in crashes would result in large error in estimating belt effectiveness, paper which Cummings dismissed as express ing "concern". ${ }^{3}$ Cummings claims that his comparison of NASS investigators' reports and police reports of belt use support the non-differential classification theory but that assumes that the NASS investigators possess the gold standard for assessing belt use. One of the major criteria for acceptance of research findings is plausibility. The risk ratios derived from post-1984 FARS and NASS data are not plausible given changes in belt use and death rates controlling for other factors.

So what is the big deal if seatbelts are standard equipment and reduce injury? Excessive claims of belt effectiveness lead to overemphasis on increasing belt use to the neglect of other needed policies. Belt use in the US is near $70 \%$ and yet about 32000 occupants of passenger cars, sport utilit vehicles, and light trucks are dying each year in collisions. In recent US Congressional hearings on sport utility vehicles, for example spokespersons for the auto industry claimed that belt use is low in fatal sport utility vehicle rollovers, based on erroneous police reports in FARS, as if low belt use absolved the industry of making stable vehicles. If belt use were $100 \%$, many people would nevertheless die and be maimed in rollovers of vehicles that are unnecessarily unstable.

Assessing belt use after the fact of a rollove is particularly problematic because crash forces in the body area where the belt touches the person are less severe in a laterally rotating vehicle than in more direct impacts with other vehicles and objects, so that belt marks on the torso may be less evident and damage to the belts is less likely. People die more from head injury when the roof crushes in, or they impact surfaces external to the vehicle if they are ejected. Police officers, and apparently NASS investigators, too often assume that an ejected occupant was unbelted when, in fact, rotation of the vehicle results in occupant slippage out of belts in some cases and belts becoming unlatched due to impact on the latches in others. In both rollovers and non-rollovers, crash investigators may assume non-use of belts simply because the occupant died.

In a second letter, Koepsell et al also misrepresent what I wrote about their illconsidered use of imputation of missing values. ${ }^{4}$ They quote my statement, “... missing data on velocity changes in crashes were imputed partly from injury severity scores, again a cause imputed from an effect and then used as a control in the study, a true scientific 'no-no'". They construe that statement as saying that "Robertson argues that measure of crash outcome should not be used to impute values on a covariate which will later enter the main analysis as a predictor of crash outcome". In fact, I would not publish a study if I had to rely on imputed data. In my opinion, their study should not have been done or published, given that more than $40 \%$ of cases in NASS have missing values of delta- $\mathrm{V}$ and the seatbelt use assessment contains the serious biases noted previously. If someone imputed values on a variable in more than $40 \%$ of the cases of an evaluation of efficacy and safety of a drug, the study would not likely be published or taken seriously if it was. Why should any less be acceptable in the study of injury control measures?

As a previous admirer of a substantial proportion of the research produced at the University of Washington's Injury Prevention and Research Center by several of these same authors, it pains me to see them produce foolish papers and attempt to discredit a critic by distorting the criticism.

L S Robertson

11 Dixon Court, Nogales AZ 85621, USA nanlee@direcway.com

\section{References}

1 Cummings $\mathbf{P}$, Rivara FP. Misclassification of seat belt use Ini Prev 2003.9.91.

2 Robertson LS. Bias in estimates of seat belt effectiveness. Inj Prev 2002;8:263.

3 Robertson LS. Estimates of motor vehicle seat belt use and effectiveness and use: implications for occupant crash protection. Am J Public Health 1976;66:859.

4 Koepsell TD, Rivara FP, Grossman DC, et al. Bias in estimates of belt effectiveness. Inj Prev 2003;9:91.

\section{Precautionary principle}

I had a hard time digesting the preemptive strike doctrine of the Bush Administration until I read your editorial on the precautionary principle in a recent issue of Injury Prevention. ${ }^{1}$ Your piece helped me regain my sanity in the seemingly insane world. When it comes to the precautionary principle, we in the injury prevention field lag behind not only those in environmental health but also those in politics. Isn't the war in Iraq an application of the precautionary principle? You did an admirable job in arguing against the timehonored notion of science preceding policy. The precautionary principle, if expanded to law, would give the benefit of doubt to the accuser instead of the accused. Thank you for penning such a thought provoking commentary!

G Li Department of Emergency Medicine, Johns Hopkins
University School of Medicine, 1830 E Monument Street, Suite 6-100, Baltimore, MD 21205 , USA ghli@jhmi.edu

\section{References}

Pless IB. Expanding the precautionary principle. Inj Prev 2003;9: 1-2.

\section{BOOK REVIEWS}

\section{Accidental Injury: Biomechanics and Prevention. 2nd Ed.}

Edited by Alan M Nahum and John W Melvin. (Pp 577; \$165.00.) Springer-Verlag, 2001. ISBN 0-387-98820-3.

Accidental Injury: Biomechanics and Prevention attempts to address the communication gap between engineering researchers studying the applied biomechanics of injury and medical personnel who diagnose and treat traumatic injury. This reference book is a compendium of chapters that review the state-of-the-art in applied biomechanics research and has been revised, updated, and expanded from its first edition in 1993. There is a chapter each on particular body regions as well as chapters on related topics such as "Anthropomorphic test devices" (chapter 4), "Instrumentation in experimental design" (chapter 2 ), and "Occupant restraint systems" (chapter 8). New chapters include "Injury risk assessments based on dummy responses" (chapter 5), "Airbag inflation-induced injury biomechanics" (chapter 9), and "Pediatric biomechanics" (chapter 21)

The two editors, Alan Nahum, MD and John Melvin, PhD are recognized leaders in trauma medicine and injury biomechanics. In this volume they have brought together many of the seminal researchers in the fields of biomechanics and human traumatic injury research. The author of each chapter is an internationally recognized expert in the field who builds on his/her direct experience with these topics to provide an exhaustive review.

The target audience for this book includes physicians, attorneys, biomedical researchers, and mechanical, biomedical, and automotive engineers. Injury prevention professionals with limited engineering background may find the technical and theoretical treatment of the injury mechanisms contained in many of the chapters too detailed and complex and may find the language not accessible. Most of the chapters have little in the way of a synopsis or practical injury prevention applications of the research findings.

A few chapters deserve special mention for their relevance to this audience. "Occupant restraints systems" by Rolf Eppinger (chapter 8 ) provides a very readable discussion of the principles of physics that govern the performance of seatbelts and airbags and identifies many upcoming technological developments highlighting their advantages and disadvantages. "Child passenger protection" by Kathleen Weber (chapter 21) quickly reviews some of the concepts discussed in more detail in chapter 8 and thoroughly describes how these principles apply to children. There is valuable collection of line drawings clearly illustrating the different types of child restraint systems.

The value of this book for the above stated audiences is that it can provide direction in understanding decades of biomechanics research by identifying key references for each topic. It is for this reason that Accidental Injury should be considered a crucial reference book for anyone involved in biomechanical research of traumatic injury. Many of these references are in engineering conference proceedings that would not appear in any traditional Medline literature search. Although not stated in the book, many of the references can be obtained through the Society of Auto motive Engineers publications library at www.sae.org. For physicians who have relied on medical journals to remain current on this type of research, this book will open the gateway to an extremely rich and robust paralle body of literature of which they may have previously been unaware. Due to the technical nature of many of the topics, the book may encourage joint study of a topic by both medical personnel and engineering researchers thereby enhancing their research efforts.

K Arbogast

Associate Director of Field Engineering Studies, TraumaLink, The Children's Hospital of Philadelphia

F Winston

Assistant Professor of Pediatrics, University of Pennsylvania and Director, TraumaLink The Children's Hospital of Philadelphia 
Looking Beneath the Surface of

Dennis J Murphy. (Pp 104.) Published by American Society of Agricultural Engineers, 2003 (ASAE Pub 801M0303). ISBN 1-802769-28-X

Agriculture is a very dangerous occupation and a complex industry. Health and safety initiatives must account for a wide spectrum of variables such as economic conditions; technology; minimal regulatory controls; the range in workers ages; and many issues influenced by culture, ethnicity, and tradition. Despite a significant increase in federal fund ing for agricultural health and safety since 1990, when compared with other occupations, the expected reduction in injuries has no occurred. Agricultural health and safety specialists are often perplexed and frustrated with the minimal impact of their efforts.

Dennis Murphy is a national authority on agricultural health and safety, with three decades' experience in the field. This 100 pag book is the result of a recent sabbatical at the National Institute for Occupational Safety and Health (NIOSH) which he used to trace the roots of the agricultural health and safety movement, to analyze major influences on safety initiatives, and to suggest strategies for the future.

There are seven chapters, each having a broad introduction and a clearly stated sum mary. Ample tables, figures and appendice highlight major points, and references are clearly and accurately cited. In the first three chapters the author argues that agricultura safety and health has been "compassion driven" rather than "evidence" or "theory driven" and provides the background for understanding both the opportunities and barriers created by the multidisciplinary nature of agricultural health and safety. Major programs, including the NIOSH-led National Initiative, are then described.

Chapter 4 provides an excellent overview of major challenges to agricultural safety and health. The author describes what he calls the farm safety-risk paradox, the incongruence between farm people's safety knowledge, values, and practices. This paradox appears throughout the book, with suggestions on methods to understand and address it through evaluative research during progressive stages of program development and implementation. There is analysis of why agricultural injury surveillance methods are plagued with problems and why, despite noble efforts to collect national level data, the true picture of agricultural injuries (especially non-fatal) eludes us. Chapters 5 and 6 address the strengths and weaknesses of applying behavioral and/or adult learning theories to agricultural safety and health interventions. The author implies that federal funds should be limited for injury surveillance as well a cognitive research to uncover reasons for behavior (except where policy and children are involved); arguing for greater emphasis on partnerships with agribusinesses and adoption of industry behavior based safety programs that integrate workers in problem identification and safety solutions. The last chapter summarizes the author's review in a "spirit of constructive reflection", providing nine suggestions and recommendations for action.

The review and analysis, with the author's reflections and recommendations, are important because they represent the most analytic review of the agricultural health and safety movement since its inception in the early 1900s, and more importantly, since federal initiatives were undertaken in 1989. Given the author's reputation in this area, his views on past successes and failures, and suggestions for the future, are likely to be read carefully by leaders in both the public and private sector.

While the book is a major contribution to the field, it has limitations, some of which the author points out. The author was immersed within NIOSH while conducting this review, so that the valuable experiences of other federal agencies (for example, US Department of Agriculture), other developed countries (for example, Sweden, Australia) with lower agricultural injury rates, and private sector endeavors (for example, tractor manufacturers' ROPS rebates) are not sufficiently reflected in this "look beneath the surface". The past and potential impact of engineering and policy strategies are almost totally neglected. Further, the author's review and recommendations primarily address traditional, modest sized family farms, without explaining why we should focus on their health and safety issues, knowing that they differ from the rapidly expanding industrialized production sites.

Dr Murphy's 1992 text, Safety and Health for Production Agriculture is a primer for those new to agricultural health and safety; professionals currently working in agricultural safety and health should definitely read Looking Beneath the Surface. It helps us appreciate our roots, and to understand our compassion as well as our frustrations as we strive to protect the adults and children who produce our food and fiber. The author challenges us to set a single national agenda and reshape the direction of major initiatives, including the NIOSH Ag Centers. Ideally, this book will stimulate discussions that lead to consensus and ultimately, action among injury preventionists who deal with agricultural populations.

B Lee

National Farm Medicine Center, Wisconsin, USA Lee.Barbara@mcrf.mfldclin.edu

\section{The Tipping Point: How Little Things Can Make a Difference.}

By Malcolm Gladwell. (Pp 279; US\$14.95.) Little, Brown and Company, January 2002. ISBN 0-349-11346-7.

The Tipping Point, first published as articles in the New Yorker and then in book form in 2000 offers a fascinating look at a concept well known to public health professionals-the epidemic. The book takes the concept a step further to examine social epidemics. In the age of AIDS and SARS, Malcolm Gladwell offers insights that might be of use in examining new epidemics, as we observe the social and health impact of epidemics on individuals, institutions, and economies. The book is never less than engaging and erudite, if occasionally a bit redundant.

Gladwell, a former science writer, has a gift for explaining the complex in clear, entertaining language. To illustrate his message he uses examples such as children's shows, shoes, direct mail marketing, and Paul Revere's ride. With engaging wit and a nuanced perspective he analyses exactly how and why the contagion caught and each issue became an epidemic. Public health professionals might take particular note of his views on the "epidemic" of smoking among teens and young adults.
The moment when epidemics change and reach their critical mass is called "The tipping point", a point borrowed from epidemiology. Gladwell recognised that tipping points might happen anywhere and began to look for examples. "The best way to understand the dramatic transformation ... or any number of the other mysterious changes that mark everyday life", he writes "is to think of them as epidemics. Ideas and products and messages and behaviours spread just like viruses do"

Though the book regularly refers to epidemics in the well known context, its message primarily relates to starting epidemics, not stopping them. Gladwell wants people to start "positive" epidemics of their own. He feels that the concept could work for those trying to reate a change with limited resources, citing examples such as a breast cancer activist who wanted to spread knowledge and awareness of breast cancer and diabetes in a particular community. He accomplishes this by presenting a kind of blueprint for the rise of any social epidemic.

Comprehending the tipping point and its role in social epidemics involves understanding three "rules": the law of the few, the stickiness factor, and the power of context. Gladwell contends that creating an epidemic involves a few agents of change or influential people to deliver the message. The "stickiness factor" or the change in the message that makes it more contagious or memorable can also be very powerful. Even small changes can make a difference in how a message sticks with us. Finally, the tipping point can occur in context or within the environment in which the message must thrive and spread. If the context in which a message is delivered isn't working or tipping, change it to suit the potential contagion more effectively.

The message Gladwell imparts is essentially a positive one-in a confusing and often counterintuitive world, "tipping points are a reaffirmation of the potential for change and the power of intelligent action". This is an idea in which all of us can take comfort.

Injury Prevention Consultant, London; a.seay@btopenworld.com

\section{Getting Research Findings into Practice. 2nd Ed.}

Edited by Andrew Haines and Anna Donald (Pp 240; £19.95.) London: BM Publishing Group, November 2001. ISBN 0-7279 1257-7.

This book is a response to the ongoing interest in the uptake of research findings. The editors have covered a broad spectrum of the issues related to translating research findings into clinical practice. The list of authors and contributors from around the world is both comprehensive and impressive.

The book starts out with basic information chapters that cover such topics as establishing criteria for the implementation of research evidence, sources of information on clinical effectiveness, and dissemination methods. Included in the information chapters is an overview of systematic reviews related to the implementation of research findings by healthcare personnel. For example, the authors provide summaries of the results of 41 systematic reviews, including almost 1500 studies.

Subsequent chapters related to implementing research findings into practice give severa 
examples from clinical practice (mainly from obstetrics), and discuss the challenges of implementation, how to use research results in the translation into practice, and an overview of the barriers and bridges to evidence based clinical practice. One chapter addresses the unique challenges of implementing research findings in developing countries.

There are some practical guidelines and tools. The two chapters on decision support and decision analysis, for example, provide both theoretical and practical information about how to conduct and apply decision analysis. The concept of opportunity costs and new options for encouraging implementation of results from economic evaluations are also addressed.

The chapter on evidence based policy making is the one most likely to be relevant to injury prevention researchers. It is also the only chapter to mention injury prevention strategies. The authors mention legislation as one policy that may arise from strong evidence. The author of this chapter, however, does not appear to support legislation as an element of policy. "Typically, therefore, legislation requires much stronger evidence before it can be introduced, particularly when paternalistic legislation designed to protect one group may harm others". Citing the introduction of seatbelt legislation as one example of legislation, the author of this chapter points out that seatbelt legislation was not enacted until the evidence for the effectiveness of seatbelts was strong. No further mention of injury prevention initiatives ensues, in fact much of the rest of the policy chapter focuses on screening programs as policies.

While well written and essential reading for those in clinical practice, the book is of limited use to most injury prevention researchers. The examples are primarily related to how to get clinicians (mostly doctors) to change their practice to reflect current evidence. Although some of the tools and concepts (such as decision analysis) are broadly applicable, those who are searching for the best way to translate injury prevention research into evidence based practice will be disappointed For multifaceted problems such as those typically encountered in injury prevention, both the evidence and the translation into practice are notably absent here.

A K Macpherson

CIHR Postdoctoral Fellow, Institute for Clinical Evaluative Sciences, Canada alimacpherson@yahoo.ca

\section{CORRECTION}

We regret that due to an oversight the acknowledgements were omitted from the paper by Sorenson and Vittes published in the June issue (Sorenson SB, Vittes KA. Buying a handgun for someone else: firearm dealer willingness to sell. Inj Prev 2003;9:147-50). The acknowledgements are as follows:

The authors would like to thank Jeff Sinek of the Los Angeles office of Thelen, Reid and Priest LLP and Eric Gorovitz of the Coalition to Stop Gun Violence for their legal research, Eugene Volokh and Mark Chekal for their comments on previous drafts, and Anthony DiStefano for his help with data collection.

\section{CALENDAR}

\section{9th International Traffic Medicine Conference 2003, Budapest, Hungary}

14-17 September 2003. Details: www.itma2003.hu.

\section{Canadian Injury Prevention Conference 2003, Ottawa}

23-25 November 2003. The meeting will build on the national conference held in 2000 and will focus on unintentional injury, violence, and suicide prevention. Organised jointly by Smartrisk, Safe Kids Canada and the Safe Communities Foundation, it aims to highlight the latest science and best practices in policy and programs; bridge the gap between research and practice by highlighting specific policy and practice recommendations stemming from Canadian research and targeted research needs identified through community practice; encourage networking and collaboration between different sectors to promote action and policy change; facilitate participation from stakeholders representing vulnerable populations; build momentum for sustained action from stakeholders at the municipal, regional, provincial and national levels; and further the activities of the Canadian Injury Research Network and the Canadian Institutes for Health Research in building capacity in injury research and knowledge translation fields. Details: www.safekidscanada.com/CIPC/default.html

\section{Lifesavers Conference: National Conference on Highway Safety Priorities. San Diego, California}

28-30 March 2004. Details: www.lifesavers conference.org.

\section{7th World Conference on Injury Prevention and Safety Promotion, Vienna}

6-9 June 2004. The major objectives of the conference are strengthening violence and injury prevention as an aspect of national public health policy and programs; producing synergy of the combined efforts of various violence and injury prevention disciplines; exchanging the most recent experiences in research and practice; and facilitating participation of experts from low income countries. Details: www.safety2004.info.

\section{LACUNAE}

\section{Measured responses to improve safety}

- ven in serious matters there can be something to laugh at. Privacy International has sifted through

5000 nominations from 35 countries to find awardees for stupid mechanisms for increasing security. The Delta Terminal at JFK Airport in New York won an award for flagrant intrusion by forcing a woman to drink three bottles of her own breast milk for fear the bottles contained explosives or chemicals. London's Heathrow Airport won an award for quarantining a quantity of "Gunpowder" green teathe tea was released but the labels were confiscated and destroyed. Australians will be proud that the national \$15 million (US\$ 9m) campaign to educate Australians about terrorism won the Most Egregiously Stupid Award. The kit, including a fridge magnet, urged them to report anything suspicious while asking them to be "alert but not alarmed" (from the Sydney Morning Herald, April 2003; submitted by Ian Scott). 